\title{
ADUBAÇÃO COM POTÁSSIO E NITROGÊNIO EM TRÊS CÍCLOS DE PRODUÇÃO DA BANANEIRA cv. PRATA-ANÃ ${ }^{1}$
}

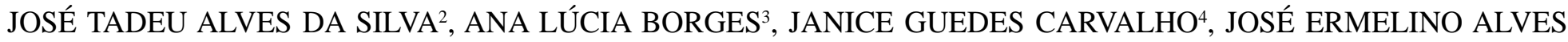 \\ DAMASCENO 5
}

RESUMO - O nitrogênio, depois do potássio, é o elemento mais exigido pela bananeira. O desbalanço entre $\mathrm{N}$ e K afeta a produção e a qualidade do fruto de banana. O objetivo deste trabalho foi avaliar a influência das adubações com nitrogênio e potássio na produção da bananeira c.v. Prata-Anã (grupo genômico AAB). O experimento foi realizado em Latossolo Vermelho-Amarelo na região do Semi-árido do Norte de Minas Gerais e irrigado por microaspersão. Estudaram-se cinco doses de $\mathrm{N}\left(0 ; 200 ; 400 ; 800\right.$ e $\left.1600 \mathrm{~kg} \mathrm{ha}^{-1} \mathrm{ano}^{-1}\right)$ e cinco doses de $\mathrm{K}_{2} \mathrm{O}\left(0 ; 200 ; 400 ; 800 \mathrm{e} 1600 \mathrm{~kg} \mathrm{ha}^{-1} \mathrm{ano}^{-1}\right)$, em esquema fatorial (5x5), durante o $2^{\circ}, 3^{\circ}$ e $4^{\circ}$ ciclos de produção. A aplicação de doses crescentes de $\mathrm{N}$ elevou o teor de Mn nas folhas acima da faixa adequada, promovendo queda na produção de banana no $2^{\circ}$ e $3^{\circ}$ ciclos. Portanto, infere-se que o teor de Mn nas folhas atingiu nível tóxico. Houve efeito do K sobre a produção de banana apenas no $4^{\circ}$ ciclo. A produção máxima de banana no $4^{\circ}$ ciclo foi obtida com a aplicação de $962,5 \mathrm{~kg}$ de $\mathrm{K}_{2} \mathrm{O}$ ha $^{-1}$ ano ${ }^{-1}$. Não ocorreu interação significativa entre $\mathrm{N}$ e K.

Termos para indexação: bananeira, nutrição, adubação.

\section{FERTILIZATION WITH NITROGEN AND POTASSIUM ON IRRIGATED BANANA CROP cv. 'PRATA-ANÃ', IN THREE CYCLES}

\begin{abstract}
Nitrogen, after potassium, is the chemical element most required by banana crop. This work evaluated the effect of nitrogen and potassium fertilization on irrigated banana crop (Prata-Anã, AAB) yield. Five rates of $\mathrm{N}\left(0,200,400,800\right.$ and $\left.1600 \mathrm{~kg} \mathrm{ha}^{-1} \mathrm{year}^{-1}\right)$ and five rates of $\mathrm{K}_{2} \mathrm{O}$ $\left(0 ; 200 ; 400 ; 800\right.$ and $1600 \mathrm{~kg} \mathrm{ha}^{-1}$ year $\left.^{-1}\right)$, in a (5x5) factorial design were studied. The data were obtained during three yield cycles (second, third and four cycles), on an eutrofic Red-Yellow latosol, sandy-clay, in the North of Minas Gerais State, Brazil. The content of Mn have increased in the leaves with the increased amount of $\mathrm{N}$ applied in the soil. The banana yield reduced with the rise of the Mn content in the leaves, on the second and third cycle. The maximum yield was obtained with the application of $962,5 \mathrm{~kg}_{\text {of }} \mathrm{K}_{2} \mathrm{O}^{-1} \mathrm{year}^{-1}$, on the fourth cycle. No interaction between $\mathrm{N}$ and $\mathrm{K}$ was found.
\end{abstract}

Index terms: banana, nutrition, fertilization.

\section{INTRODUÇÃO}

A produção de banana é influenciada por fatores internos da planta, como os genéticos, e fatores externos, que são as condições de clima, solo e manejo agronômico praticado na cultura, como a adubação. Segundo Lopez \& Espinosa (1995), a nutrição é um fator de produção de extrema importância para a bananeira devido à alta eficiência destas plantas em produzir grandes quantidades de fitomassa em curto período de tempo.

A bananeira é uma planta sensível ao desequilíbrio nutricional. Para elevar a produtividade e melhorar a qualidade dos frutos de banana, é importante manter no solo o equilíbrio entre os nutrientes, evitando que ocorra consumo excessivo de um elemento, induzindo deficiência de outro (Gutierrez, 1983).

O nitrogênio, depois do potássio, é o elemento mais exigido pela bananeira (Silva, 1994). Ele é mais importante no início do desenvolvimento da planta até a emissão da inflorescência; além disso, influencia não somente o número de frutos e de pencas por cacho, como também o desenvolvimento radicular quando associado ao potássio (Gomes, 1988).

O desbalanço entre $\mathrm{N}$ e K causa problemas na pós-colheita, pois o baixo suprimento de potássio favorece o acúmulo de nitrogênio amoniacal, que induz o amadurecimento precoce e a produção de frutos magros. O excesso de $\mathrm{N}$ atrasa a emergência do cacho, o que favorece a produção de cachos fracos e pencas separadas. Nos vários países produtores de banana, as doses de potássio recomendadas variam de 100 a 1200 $\mathrm{kg}$ de $\mathrm{K}_{2} \mathrm{O} \mathrm{ha}^{-1} \mathrm{ano}^{-1} \mathrm{e}$ a de nitrogênio de 100 a $600 \mathrm{~kg}$ de $\mathrm{N} \mathrm{ha}^{-1} \mathrm{ano}^{-1}$.

Em experimento conduzido por Guerra et al. (1986), com a banana-“Branca"(Subgrupo Prata), verificaram que não houve efeito do N no peso do cacho; entretanto, para o potássio, observaram aumento significativo em relação à testemunha a partir da dose de $400 \mathrm{~kg}$ de $\mathrm{K}_{2} \mathrm{O} / \mathrm{ha}$. Ferreira (1995) verificou que o excesso de calagem na bananeira cultivar "Myssore" resultou em queda na concentração do potássio na folha, com decréscimo no peso do fruto e no peso do cacho.

Segundo Silva (1994), os programas de adubações para as bananeiras c.v. Prata-Anã (AAB) sob irrigação, no Norte de Minas Gerais, são baseados em recomendações utilizadas para o cultivo da bananeira em condições de sequeiro, o que tem induzido o aparecimento de sintomas de desbalanço nutricional e, conseqüentemente, queda na produtividade e na qualidade do fruto de banana.

O objetivo deste trabalho foi avaliar a influência das adubações com nitrogênio e potássio na produção da bananeira c.v. PrataAnã (AAB).

\section{MATERIAL E MÉTODOS}

O ensaio foi conduzido de maio/1994 a julho/1999, em Latossolo Vermelho-Amarelo (Tabela 1), no município de Nova Porteirinha, localizado na região Semi-árida do Norte de Minas Gerais. A temperatura e a pluviosidade média anual nesta região são de $26^{\circ} \mathrm{Ce} 910 \mathrm{~mm}$, respectivamente.

No plantio da bananeira c.v Prata-Anã, do grupo genômico (AAB), utilizaram-se mudas originadas de cultura de tecido. $\mathrm{O}$ espaçamento utilizado no plantio das mudas foi 4,5 x 3,5 x 2,0 m (1.250 plantas/ha). O ensaio foi irrigado diariamente por microaspersão, onde foram aplicadas lâminas equivalente a $80 \%$ da evaporação do tanque Classe A. Os tratos culturais foram realizados conforme Souto et al.

\footnotetext{
${ }^{1}$ Trabalho (145/2001). Recebido: 20/01/2002; Aceito para publicação: 20/03/2003

${ }^{2}$ Eng. Agro. M. S. Pesquisador da EPAMIG Caixa Postal 12. CEP 39440-000, Janaúba-M.G. Telefone-(38) 38212160 Email: tadeu@ufla.br

${ }^{3}$ Eng. Agra. Dra. Pesquisador da Embrapa Mandioca e Fruticultura. C.Postal 007. CEP 44380-000, Cruz das Almas-BA. Telefone- (75) 721 2120 E-mail: analucia@cnpmf.embrapa.br

${ }^{4}$ Eng. Agra. Dra. Prof. Titular, Dep. de Solos, Universidade Federal de Lavras. Caixa Postal 37. CEP 37200-000, Lavras-MG. Telefone- (35) 3829 1252 E-mail: janicegc@ufla.br

${ }^{5}$ Bacharel em Matemática, Prof. Assistente, Dep. de Ciências Exatas, Universidade Estadual de Montes Claros. CEP 39401-089, Montes Claros-MG. E-mail: ermelinod@bol.com.br
} 
(1997). Os tratamentos foram distribuídos no delineamento experimental de blocos casualizados, com quatro repetições, em esquema fatorial $5 \mathrm{x}$ 5 , correspondentes a cinco doses de $\mathrm{N}(0 ; 200 ; 400 ; 800$ e $1600 \mathrm{~kg}$ ha ${ }^{1}$ ano $\left.^{-1}\right)$ e cinco doses de $\mathrm{K}_{2} \mathrm{O}\left(0 ; 200 ; 400 ; 800\right.$ e $\left.1600 \mathrm{~kg} \mathrm{ha}^{-1} \mathrm{ano}^{-1}\right)$. Estas doses foram parceladas e aplicadas mensalmente. As fontes de nitrogênio e potássio foram uréia e cloreto de potássio, respectivamente.

TABELA 1- Propriedades químicas do solo na profundidade de 0 a 20 $\mathrm{cm}$ e 20 a $40 \mathrm{~cm}$

\begin{tabular}{|c|c|c|c|c|c|c|c|c|c|}
\hline $\begin{array}{l}\text { Profund. } \\
\text { (cm) }\end{array}$ & $\begin{array}{c}\mathrm{pH} \\
\text { (Água) }\end{array}$ & $\begin{array}{l}\mathrm{H}+\mathrm{Al} \\
\mathrm{Al}\end{array}$ & $\mathrm{Ca}$ & $\mathrm{Mg}$ & & CTC & $\mathrm{P}^{1}$ & M.O & V \\
\hline & & $\ldots$ & $\ldots$ & $\mathrm{bol}_{\mathrm{c}} \mathrm{d}$ & $n^{-3}-\ldots$ & -1 & $\mathrm{~g} \mathrm{dr}$ & ${ }^{3} \mathrm{~g} \mathrm{k}$ & $-\%-$ \\
\hline 20 & 6,2 & $2,3 \quad 0,0$ & 5,1 & 1,4 & 0,54 & 9,3 & 5,0 & 24 & 80 \\
\hline $20-40$ & 6,0 & $2,1 \quad 0,0$ & 4,9 & 1,2 & 0,58 & 8,8 & 3,0 & - & 77 \\
\hline
\end{tabular}

${ }^{1}$ Extrator Mehlich

Cada parcela do ensaio foi constituída de 8 plantas, em $64 \mathrm{~m}^{2}$, e a parcela útil constituída de quatro plantas, em $32 \mathrm{~m}^{2}$. A adubação de plantio foi realizada com aplicação de $90 \mathrm{~g}$ de $\mathrm{P}_{2} \mathrm{O}_{5}$ na cova, sendo $40 \mathrm{~g}$ de $\mathrm{P}_{2} \mathrm{O}_{5}$ na forma de superfosfato simples e $50 \mathrm{~g}$ de $\mathrm{P}_{2} \mathrm{O}_{5}$ na forma de termofosfato de Yoorin-Mg. Em cada cova de plantio, foram aplicados, também, $50 \mathrm{~g}$ de FTE BR-12 como fonte de micronutrientes. O ensaio foi conduzido até o $4^{\circ}$ ciclo de produção. Os resultados do $1^{\circ}$ ciclo encontram-se em Borges et al. (1997).

Foram coletadas amostras de folhas nas plantas úteis de cada parcela conforme Silva et al. (1999). Os teores foliares de macro e micronutrientes foram determinados seguindo metodologia descrita por Malavolta et al. (1989) .

Os dados de produção de banana e de teores de macro e micronutrientes das folhas foram analisados estatisticamente, mediante análise de variância (teste F). Foram ajustadas curvas de regressão, considerando os níveis de $\mathrm{N}$ e $\mathrm{K}$ como variáveis independentes, e a produção de banana e os teores de macro e micronutrientes das folhas como variáveis dependentes.

\section{RESULTADOS E DISCUSSÃO}

A análise de variância dos dados revelou que houve efeito significativo da aplicação de $\mathrm{N}$ no solo sobre a produção de banana no $2^{\circ}$ e $3^{\circ}$ ciclos. $\mathrm{O}$ aumento das doses de $\mathrm{N}$ não influenciou a produção de banana no $4^{\mathrm{o}}$ ciclo (Tabela 2). Resultado semelhante foi obtido no $1^{\mathrm{o}}$ ciclo (Borges et al.,1997). A regressão linear foi o modelo que mostrou melhor ajuste para o efeito de $\mathrm{N}$ sobre a produção de banana. Ao contrário do que se esperava, o aumento das doses de $\mathrm{N}$ reduziu a produção de banana no $2^{\circ}$ e $3^{\circ}$ ciclos (Figura 1). Guerra et al. (1986) não observaram efeitos do N sobre a produção de banana. Entretanto, Hegde \& Srinivas (1991) verificaram que o aumento das doses de $\mathrm{N}$ elevou o número de frutos/penca, o de pencas/cacho e a produção. Resultados semelhantes a esses foram obtidos por Brasil et al. (2000), em trabalho realizado com a bananeira c.v Pioneira no Estado do Pará. Nas regiões produtoras de banana em todo mundo, as doses de $\mathrm{N}$ recomendadas para bananeira variam de 100 a $600 \mathrm{~kg} \mathrm{ha}^{-1} \mathrm{ano}^{-1}$, dependendo do solo, da cultivar e das condições climáticas de cada área. Em trabalhos realizados na Costa Rica, por vários anos, as maiores produções de banana foram obtidas com aplicação de 300 a 320 kg de $\mathrm{N} \mathrm{ha}^{-1}$ ano $^{-1}$ (Lopez \& Espinosa, 1995).

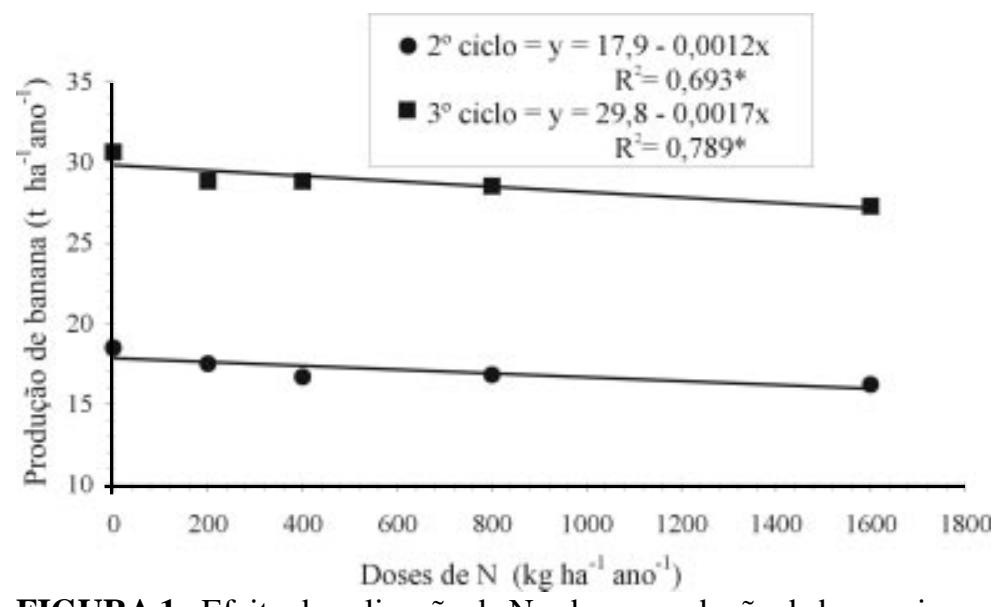

FIGURA 1 - Efeito da aplicação de N sobre a produção da bananeira

A análise de variância dos dados de teores de macro e micronutrientes nas folhas da bananeira mostrou que houve efeito da aplicação de $\mathrm{N}$ no solo sobre os teores foliares de $\mathrm{N}$ no $2^{\circ}$ ciclo; de $\mathrm{Ca}$ no $2^{\circ}$ e $3^{\circ}$ ciclos; de K e Mn no $2^{\circ}, 3^{\circ}$ e $4^{\circ}$ ciclos (Tabelas 2 e 3 ). A aplicação de doses crescentes de $\mathrm{N}$ elevou linearmente os teores de $\mathrm{N}$ nas folhas no $2^{\circ}$ ciclo e de $\mathrm{Mn}$ no $2^{\circ}, 3^{\circ}$ e $4^{\circ}$ ciclos (Figuras 2 e 3 , respectivamente). Entretanto, o aumento das doses de $\mathrm{N}$ reduziu os teores de Ca nas folhas no $2^{\circ}$ e $3^{\circ}$ ciclos e de $\mathrm{K}$ no $2^{\circ}, 3^{\circ}$ e $4^{\circ}$ ciclos (Figuras 4 e 5 , respectivamente).

TABELA 2 - Valores de F da análise de variância das variáveis produção e teores de macronutrientes das folhas da bananeira cv. Prata-Anã, obtidos no $2^{\circ}, 3^{\circ}$ e $4^{\circ}$ ciclos de produção.

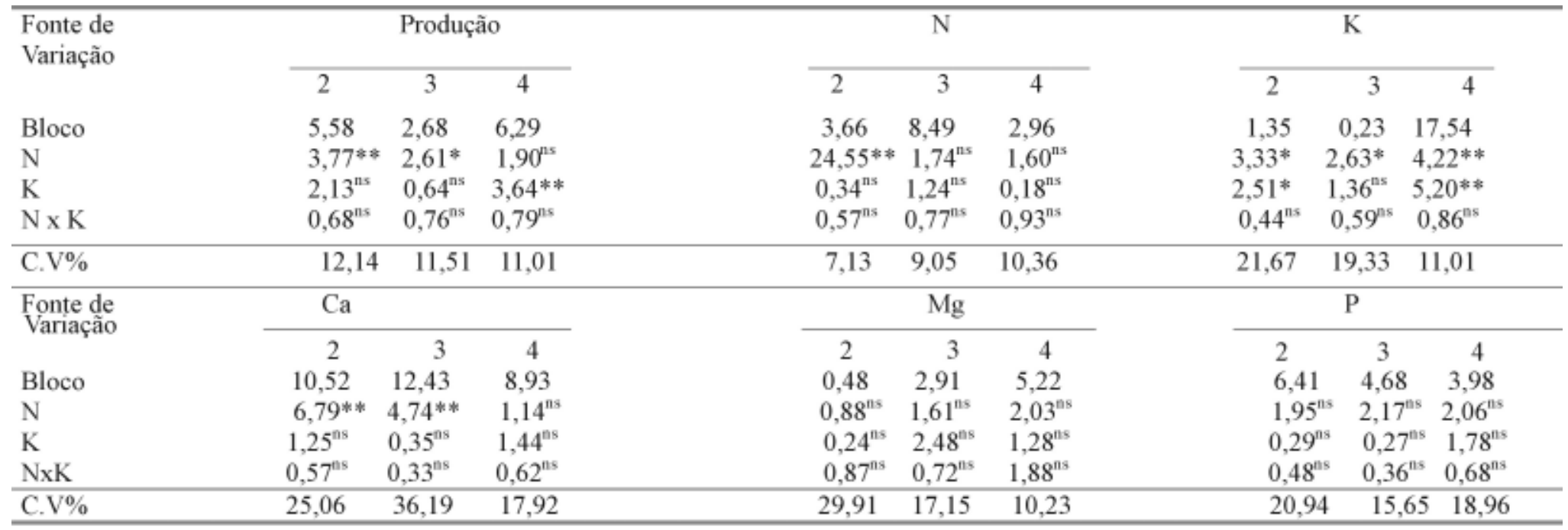

ns, * e **, não significativo, significativo a $5 \%$ e $1 \%$ de probalidade, respectivamente.

Segundo Malavolta \& Neptune (1983), a utilização de adubos fisiologicamente ácidos, a exemplo da uréia e sulfato de amônio, reduz o pH e o teor de $\mathrm{Ca}^{+2}$ trocável do solo, determinando, por outro lado, aumento no teor foliar de Mn que chega a atingir níveis tóxicos. A redução dos teores de $\mathrm{K}$ e Ca nas folhas, causada pelo aumento das doses de $\mathrm{N}$, não teve influência na queda de produção de banana, pois, mesmo assim, os teores de $\mathrm{Ca}$ e $\mathrm{K}$ mantiveram-se em níveis adequados nas folhas para obter-se alta produção de banana conforme Silva et al. (2001). Entretanto, 
o aumento do teor de $\mathrm{Mn}$ nas folhas, com o aumento das doses de $\mathrm{N}$, influenciou na queda de produção da bananeira. Segundo Silva et al. (2001), o teor adequado de Mn nas folhas de bananeira c.v Prata-Anã, cultivada no Norte de Minas, está na faixa de 250 a $500 \mathrm{mg} \mathrm{kg}^{-1}$. De acordo com a regressão da Figura 3, quando se aplicou a dose de $1600 \mathrm{~kg}$ de $\mathrm{N}$ ha ${ }^{1}$ ano $^{-1}$, os teores de Mn encontrados nas folhas foram de 875; 714 e $498 \mathrm{mg}$ $\mathrm{kg}^{-1}$, no $2^{\circ}, 3^{\circ}$ e $4^{\circ}$ ciclos respectivamente. Portanto, infere-se que os teores de $\mathrm{Mn}$ nas folhas atingiram níveis tóxicos no $2^{\circ}$ e $3^{\circ}$ ciclos, reduzindo a produção da bananeira. O interessante é que, no $4^{\circ}$ ciclo, não houve efeito significativo do $\mathrm{N}$ sobre a produção de banana, isto porque o teor de $\mathrm{Mn}$ nas folhas estava dentro da faixa adequada. Silva (2001) verificou que a aplicação de doses crescentes de $\mathrm{N}$, utilizando uréia como fonte, reduziu o pH do solo, que, por sua vez, favoreceu a elevação do teor de Mn nas folhas da bananeira. $\mathrm{O}$ autor observou correlação negativa entre a produção de banana e o teor de Mn nas folhas.

TABELA 3- Valores de F da análise de variância dos teores de micronutrientes das folhas de bananeira cv. Prata-Anã, obtidos no $2^{\circ}, 3^{\circ}$ e $4^{\circ}$ ciclos de produção.

\begin{tabular}{|c|c|c|c|c|c|c|c|c|c|c|c|c|}
\hline \multirow{2}{*}{$\begin{array}{l}\text { Fonte de } \\
\text { Variação }\end{array}$} & \multicolumn{3}{|c|}{ B } & \multicolumn{3}{|c|}{$\mathrm{Fe}$} & \multicolumn{3}{|c|}{$\mathrm{Mn}$} & \multicolumn{3}{|c|}{$\mathrm{Zn}$} \\
\hline & $2^{\circ}$ & $3^{\circ}$ & $4^{\circ}$ & $2^{\circ}$ & $3^{\circ}$ & $4^{\circ}$ & $2^{\circ}$ & $3^{\circ}$ & $4^{\circ}$ & $2^{\circ}$ & $3^{\circ}$ & $4^{\circ}$ \\
\hline Bloco & 4,03 & 10,98 & 12,51 & 10,91 & 14,54 & 13,59 & 8,80 & 11,34 & 2,96 & 7,30 & 0,86 & 11,29 \\
\hline $\mathrm{N}$ & $2,35^{\mathrm{ns}}$ & $1,49^{\mathrm{ns}}$ & $1,53^{\mathrm{ns}}$ & $2,17^{\mathrm{ns}}$ & $2,22^{\mathrm{ns}}$ & $1,54^{\mathrm{ns}}$ & $58,72^{* *}$ & $45,67 * *$ & $22,03^{* * *}$ & $1,29^{\mathrm{ns}}$ & $0,34^{\mathrm{ns}}$ & $1,27^{\mathrm{ns}}$ \\
\hline K & $0,82^{\text {ns }}$ & $1,00^{\mathrm{ns}}$ & $1,61^{\mathrm{ns}}$ & $0,06^{\mathrm{ns}}$ & $1,01^{\mathrm{ns}}$ & $0,03^{\mathrm{ns}}$ & $1,68^{\text {ns }}$ & $1,06^{\mathrm{ns}}$ & $1,41^{\mathrm{ns}}$ & $0,63^{\mathrm{ns}}$ & $0,77^{\mathrm{ns}}$ & $1,51^{\mathrm{ns}}$ \\
\hline $\mathrm{N} \times \mathrm{K}$ & $0,62^{\text {ns }}$ & $0,99^{\mathrm{ns}}$ & $0,85^{\mathrm{ns}}$ & $0,34^{\mathrm{ns}}$ & $0,83^{\text {ns }}$ & $1,00^{\mathrm{ns}}$ & $0,91^{\mathrm{ns}}$ & $0,56^{\mathrm{ns}}$ & $0,86^{\mathrm{ns}}$ & $0,81^{\mathrm{ns}}$ & $1,35^{\mathrm{ns}}$ & $1,48^{\text {ns }}$ \\
\hline C.V\% & 16,79 & 24,39 & 19,68 & 27,71 & 29,67 & 22,54 & 23,29 & 25,79 & 21,01 & 23,60 & 35,51 & 37,96 \\
\hline
\end{tabular}

ns, * e **, não significativo, significativo a $5 \%$ e $1 \%$ de probalidade, respectivamente

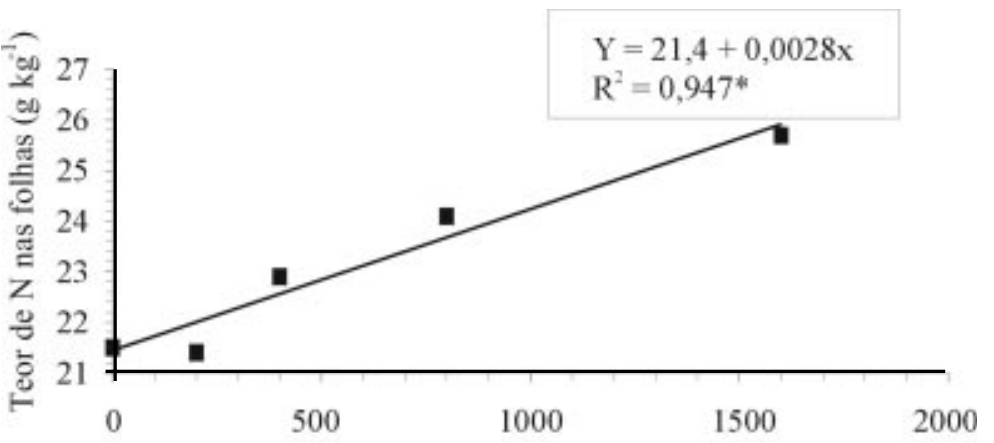

Doses de $\mathrm{N}\left(\mathrm{kg} \mathrm{ha}^{-1}\right.$ ano $\left.^{-1}\right)$

FIGURA 2- Efeito da aplicação de $\mathrm{N}$ sobre o teor de $\mathrm{N}$ nas folhas da bananeira no $2^{\circ}$ ciclo

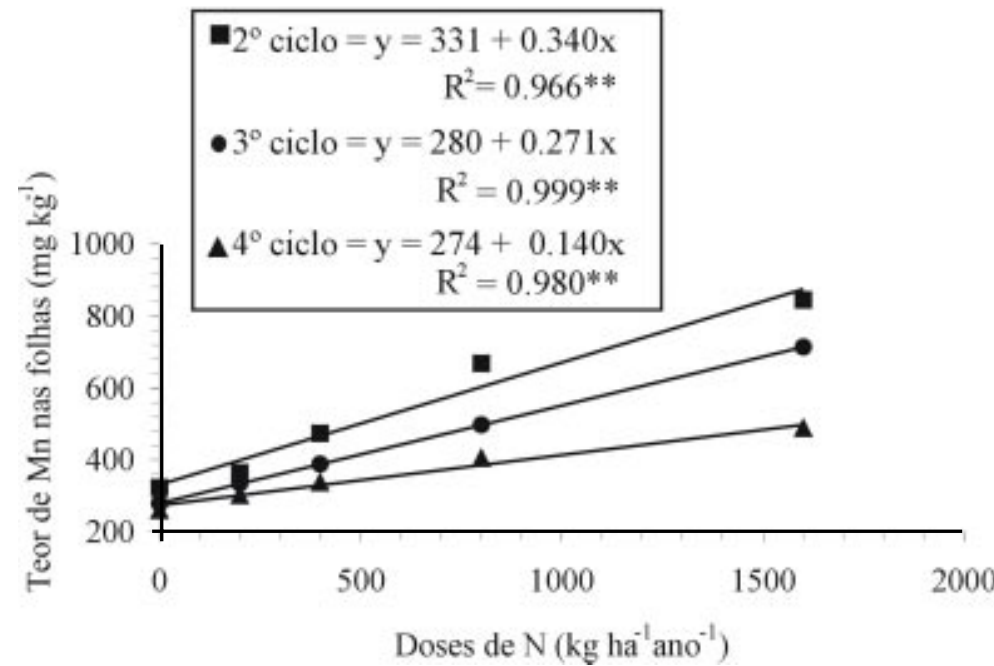

FIGURA 3- Efeito da aplicação de $\mathrm{N}$ sobre o teor de Mn nas folhas da bananeira.

A análise de variância mostrou que houve efeito significativo da aplicação do K sobre a produção de banana apenas no $4^{\circ}$ ciclo ( Tabela 2). De acordo com a análise de regressão, o modelo quadrático foi o que melhor se ajustou aos dados de produção da

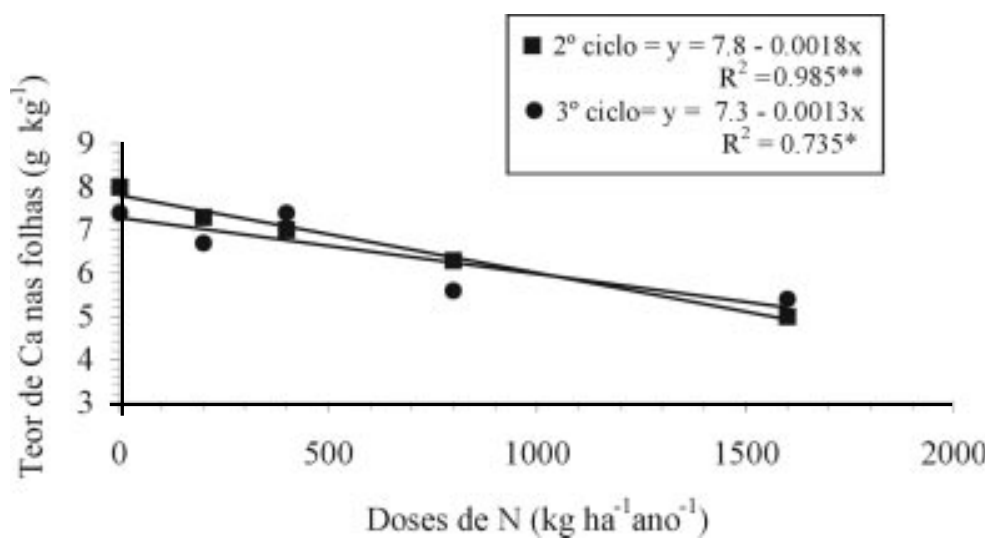

FIGURA 4- Efeito da aplicação de $\mathrm{N}$ sobre o teor de Ca nas folhas da bananeira.

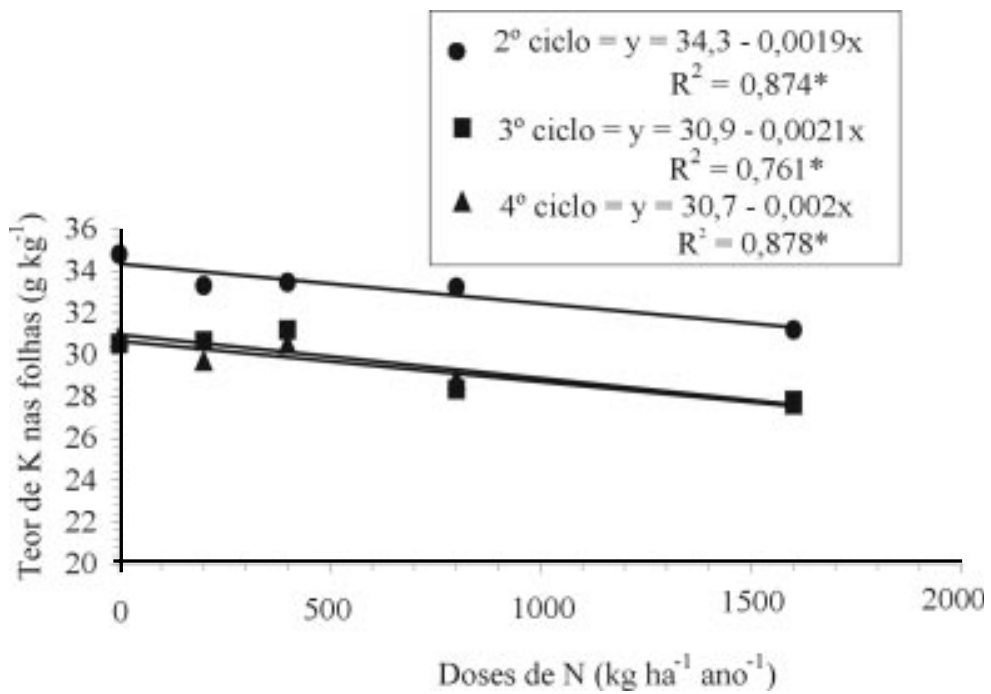

FIGURA 5- Efeito da aplicação de $\mathrm{N}$ sobre o teor de K nas folhas da bananeira.

bananeira em função das doses de $\mathrm{K}$, no $4^{\circ}$ ciclo (Figura 6). A estimativa da produção máxima foi obtida com aplicação de $962,5 \mathrm{~kg}$ de $\mathrm{K}_{2} \mathrm{O}$ ha $^{-1}$ ano $^{-1}$, promovendo um aumento de $11,2 \%$ na produção de banana em relação à testemunha. Segundo Lahav \& Turner (1983), a elevada 
demanda de K pela bananeira favorece a resposta desta planta à aplicação deste elemento mesmo em solos com teores de até $0,4 \mathrm{cmol} \mathrm{dm}$ ${ }^{3}$. O solo utilizado no presente trabalho apresentava teor de $\mathrm{K}$ acima de $0,50 \mathrm{cmol}_{\mathrm{c}} \mathrm{dm}^{-3}$ (Tabela 1). Este elevado teor de $\mathrm{K}$ disponível no solo foi o principal motivo para a baixa resposta da bananeira à aplicação deste elemento no solo. No $1^{\circ}$ ciclo, não houve efeito significativo do $\mathrm{K}$ sobre a produção de banana, ocorrendo um aumento de apenas 0,4 t ha ${ }^{-1}$ ano $^{-1}$ em relação à testemunha (Borges et al.,1997). A aplicação de doses crescentes de $\mathrm{K}$ no solo elevou o teor deste elemento, significativamente, nas folhas da bananeira no $2^{\circ}$ e $4^{\circ}$ ciclos (Figura 7). Aumentos significativos de produção de banana com a aplicação do K a partir de $400 \mathrm{~kg}$ de K$_{2} \mathrm{O} \mathrm{ha}^{-1} \mathrm{ano}^{-1}$ foram obtidos por Guerra et al. (1986). Brasil et al. (2000) obtiveram produção ótima da bananeira c.v Pioneira com aplicações de 370 e $270 \mathrm{~kg}$ de $\mathrm{K}_{2} \mathrm{O} \mathrm{ha}^{-1}$, obtendo aumentos de produção da ordem de 73 e $39 \%$, no $2^{\circ}$ e $3^{\circ}$ ciclos, respectivamente. De acordo com os autores, o solo no qual foi realizado o experimento apresentava baixa disponibilidade de $\mathrm{K}$, da ordem de $0,05 \mathrm{cmol}_{\mathrm{c}} \mathrm{dm}^{-3}$.

Não ocorreu interação significativa entre $\mathrm{N}$ e K, nos três ciclos de produção estudados.

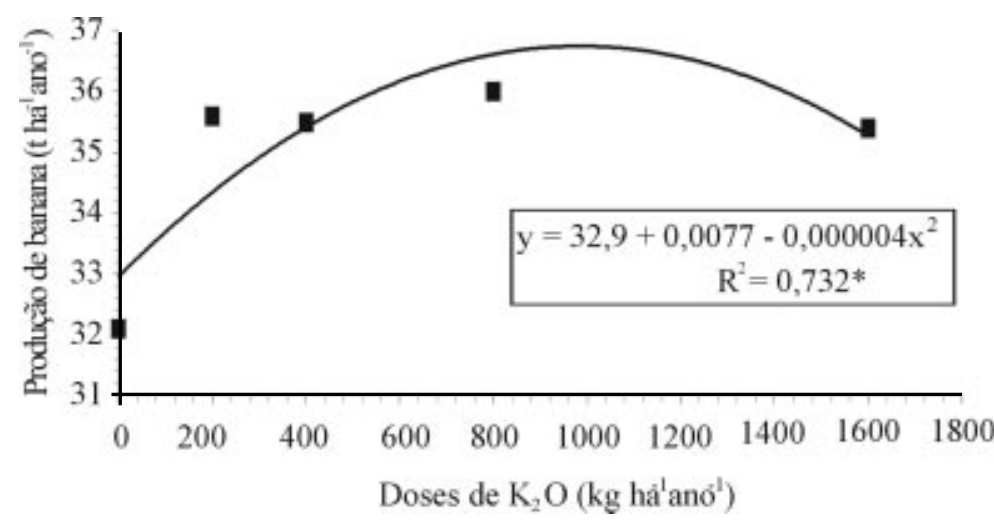

FIGURA 6- Efeito da aplicação de K sobre a produção de banana no $4^{\circ}$ ciclo

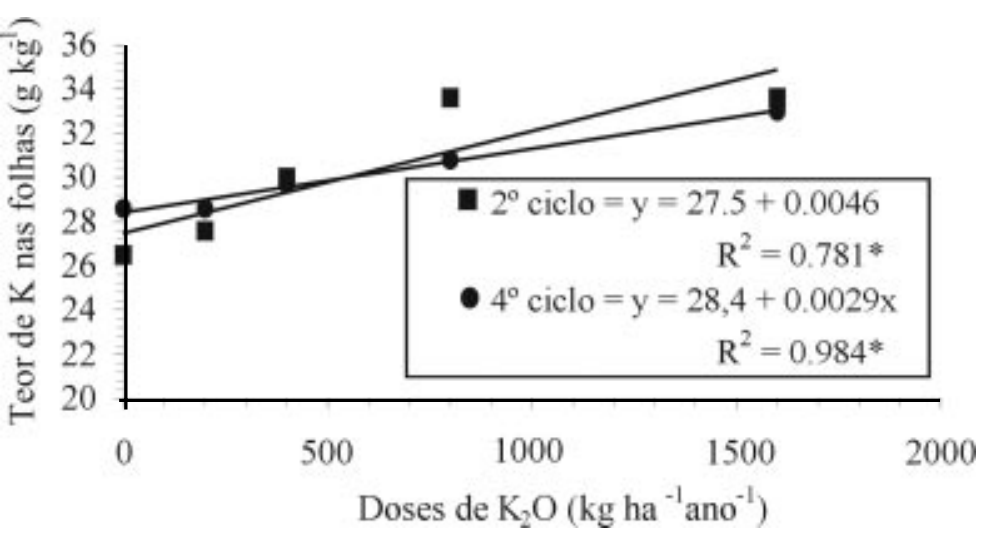

FIGURA 7-Efeito da aplicação de K sobre o teor de K nas folhas da bananeira.

\section{CONCLUSÕES}

1) A aplicação de $\mathrm{N}$ no solo elevou o teor de $\mathrm{Mn}$ nas folhas para níveis acima do adequado, reduzindo a produção da bananeira no $2^{\circ}$ e $3^{\circ}$ ciclos.

2) Houve efeito da aplicação de K sobre a produção de banana no $4^{\circ}$ ciclo, e a produção máxima foi obtida com a aplicação de $962,5 \mathrm{~kg}$ de $\mathrm{K}_{2} \mathrm{O}_{\text {ha }^{-1}} \mathrm{ano}^{-1}$.

\section{AGRADECIMENTOS}

Ao bananicultor Nuno Monteiro Casassanta, por ter concedido a área, em sua propriedade, para a realização deste trababalho .

\section{REFERÊNCIASBIBLIOGRÁFICAS}

BORGES, A . L.; SILVA, J.T. A. ; OLIVEIRA, S.L. Adubação nitrogenada e potássica para bananeira cv. "Prata-Anã" irrigada: produção e qualidade dos frutos no primeiro ciclo. Revista Brasileira de Fruticultura, Cruz das Almas, v.19, n. 2, p.179-184, 1997.

BRASIL, E. C.; OEIRAS, A. H. L; MENEZES, J.E. A.; VELOSO, C. A. C. Desenvolvimento e produção de frutos de bananeira em resposta à adubação nitrogenada e potássica. Pesquisa Agropecuária Brasileira, Brasília, v. 35, n. 12, p. 1-14, 2000.

FERREIRA, R. P. Produção e qualidade da banana "Myssore," (Musa AAB) em resposta à combinação entre doses de potássio e de uma mistura de calcário dolomítico e gesso, 1995. 68p. Dissertação ( Mestrado em Fitotecnia), Universidade Federal de Viçosa, Viçosa, 1995.

GOMES, J. A. Absorção de nutrientes pela bananeira cv. Prata (Musa AAB, subgrupo prata) em diferentes estádios de desenvolvimento, 1988. 98 p. Dissertação (Mestrado em Fruticultura), Escola Superior de Agricultura Luis de Queiroz, Universidade de São Paulo, Piracicaba.

GUERRA, M. P. ; PEDROTTI, E. L. ; REIS, M. S.; FERRARI, D. L. Resposta da bananeira-"Branca" (Grupo AAB ) a diferentes níveis de nitrogênio e potássio. In: CONGRESSO BRASILEIRO DE FRUTICULTURA, 8, 1986, Brasília, DF. Anais... Brasília, DF: EMBRAPA-DDT, 1986. v.1, p.59-64.

GUTIERREZ, C. A. L. Diagnóstico del estado nutricional de plantaciones bananeras. Asbana: 6(19):13-18, 1983.

HEGDE, D. M. ; SRINIVAS, K. Growth, yield, nutrient uptake and water use of banana crops under drip and basin irrigation with $\mathrm{N}$ and $\mathrm{K}$ fertilization. Tropical Agriculture, Trinidad, v.68, n.4, p.331-334, 1991.

LAHAV, E.; TURNER, D. W. Banana nutrition, Bern: International Potash Institute, 1983, 62p. ( IPI. Bulletin, 7 ).

LÓPEZ, M.A.; ESPINOSA, M.J. Manual de nutrition y fertilización del banano. Quito: Instituo de la Potasa y el Fósforo, 1995. 82p.

MALAVOLTA, E.; NEPTUNE, A. M. L. Características e eficiência dos adubos nitrogenados. São

Paulo: SN Centro de Pesquisa e Promoção de Sulfato de Amônio, 1983. 45p. ( SN Boletim técnico, 2).

MALAVOLTA, E.; VITTI, C. G. OLIVEIRA, S. A. Avaliação do estado nutricional das plantas: princípios e aplicações. Piracicaba, POTAFOS, 1989, 201p.

SILVA, J. T. A. Adubação e nutrição da bananeira para o Norte de Minas. Belo Horizonte-MG: EPAMIG, 1994,.24p. ( Boletim Técnico, 46).

SILVA, J. T. A. ; BORGES A. L., MALBURG, J. L. Solos, adubação e nutrição da bananeira. Informe Agropecuário, Belo Horizonte, v. 20, n. 196, p 21 - 36, jan/fev. 1999.

SILVA, J.T. A. Efeito do nitrogênio sobre o pH do solo, absorção de Mn e produtividade de bananeira cv. Prata-Anã. In: CONGRESSO BRASILEIRO DE CIÊNCIA DO SOLO, 28, 2001, Londrina. Anais... Londrina: SBCS, 2001. (CD - ROM).

SILVA, J. T. A.; BORGES, A. L.; SOUTO, R. F.; COSTA, E. L. ; DIAS, M. S. C. Levantamento do estado nutricional das bananeiras c.v. Prata-Anã do Norte de Minas Gerais. Nova Porteirinha -MG, EPAMIG/PADFIN, 2001, 30p. (Relatório Técnico de Pesquisa).

SOUTO,R.F.; RODRIGUES, M.G.V.; ALVARENGA,C.D.; SILVA, J.T.A.; MAENO,P.; GONZAGA,V. Sistema de produção para a cultura da banana-Prata-Anã no Norte de Minas. Belo Horizonte-MG. EPAMIG,1997.32p. (EPAMIG-Boletim Técnico,48). 